\title{
Bitki Yaşı ve Hasat Zamanının Kuşkonmaz Verimi ve Sürgün Kalitesi Üzerine Etkileri
}

\author{
Şebnem KÖKLÜ1 ${ }^{1}$, Sevda DOLUNBAY², Gökçen YAKUPOĞLU ${ }^{3}$, Aygül KARACA4, Abdullah HAVAN5 \\ Ahmet KOKRMAZ6 \\ 1,2,4,5,6 Kahramanmaraş Sütçü İmam Üniversitesi, Ziraat Fakültesi, Bahçe Bitkileri Bölümü, Kahramanmaraş, ${ }^{3}$ Bozok Üniversitesi Boğazlıyan \\ Meslek Yüksek Okulu, Tıbbi Aromatik Bitkiler Programı, Yozgat Türkiye \\ ${ }^{1}$ https://orcid.org/0000-0002-5769-2963, ${ }^{2}$ https://orcid.org/0000-0001-9845-1990, ${ }^{3} \mathrm{https}: / /$ orcid.org/0000-0003-4921-0925 \\ ${ }^{4} \mathrm{https}: / /$ orcid.org/0000-0001-9142-9678, ${ }^{5} \mathrm{https}: / /$ orcid.org/0000-0003-2892-681X, ${ }^{6} \mathrm{https}: / / o r c i d . o r g / 0000-0002-3886-5953$ \\ 凶: akorkmaz@ksu.edu.tr
}

\section{ÖZET}

Bu çalışmanın amacı farklı hasada başlama yaşı (2 ve 3 yaş) ve hasat zamanlarının (bahar ve yaz aylarında) kuşkonmaz verimi ve sürgün kalitesi üzerine etkilerini araştırmaktır. Bu amaçla UC $157 \mathrm{~F}_{1}$ çeşidi kuşkonmaz fideleri 2011 ve 2012 yıllarında araziye dikilmişlerdir. Hasada bitkiler iki ve üç yaşlarına geldikleri 2014 yılında başlanmış ve kuşkonmaz bitkilerinin yarısı ilkbaharda diğer yarısı da yazın hasat edilmiştir. Hasada başlama yaşı sürgün verimi ve kalitesini önemli bir şekilde etkilemiş ve 2 yaşında hasada başlanan bitkilerden daha az sayıda sürgün hasat edilmiştir. Ayrıca hasat zamanı, sürgün verimi ve kalitesini etkilemiş ve baharda hasat edilen bitkilerden daha fazla sayıda ve daha kalın sürgün hasat edilmiştir. Baharda yapılan hasat sonucunda 8-12 mm kalınlı̆ga sahip sürgün sayısı azalmış buna karşın 12-16 mm ve 16 mm'den kalın sürgün sayısında artış gözlenmiştir. Tüm bu sonuçlar kuşkonmaz bitkilerinin 2. yılda uzun dönem sürgün verim ve kalitesi üzerinde olumsuz bir etkiye sahip olmadan hasat edilebileceğini göstermiştir. Ayrıca, sürgünlerin sayısı ve kalitesi dikkate alındığında, yaz hasadının sadece ürün fiyatının yüksek olması kaydıyla bahar hasadına alternatif olabileceği görülmüştür.

\section{Araştırma Makalesi}

Makale Tarihçesi
Geliş Tarihi $\quad: 04.10 .2019$
Kabul Tarihi $\quad: 27.01 .2020$

\section{Anahtar Kelimeler}

Kuşkonmaz

Bitki yaşı

Verim

Hasat zamanı

Sürgün kalitesi

\section{The Effects of Plant Age and Harvest Time on Asparagus Yield and Quality}

\section{ABSTRACT}

The objective of this study was to determine the effect of harvest time and the age at first harvest after transplanting (2 and 3 years old) on asparagus yield and spear quality. For this purpose, UC $157 \mathrm{~F}_{1}$ variety asparagus seedlings were transplanted in the field in 2011 and 2012. Harvesting started in 2014 when the plants were 2 or 3 years old and half of the asparagus plants were harvested in the spring while the other half in the summer. Plant age significantly affected the spear yield and spear thickness with younger plants producing fewer spears. In addition, harvest time also had a significant effect on the number of spears per plant harvested and spear quality. Harvesting asparagus in the spring resulted in higher number of spears per plant and thicker spears. Harvesting in the spring also caused fewer number of spears per plant having a thickness of 8-12 $\mathrm{mm}$ but resulted in more spears having a diameter of 12-16 $\mathrm{mm}$ or thicker than $16 \mathrm{~mm}$ in comparison with summer harvest. All these results clearly indicated that harvesting could begin in the second year without any significant longterm effect on spear yield and quality. Moreover, considering the spear yield and quality, summer harvests could be an alternative to spring harvests only if the market prices are higher.

\section{Research Article}

$\begin{array}{ll}\text { Article History } & \\ \text { Received } & : 04.10 .2019 \\ \text { Accepted } & : 27.01 .2020\end{array}$

Keywords

Asparagus

Plant age

Yield

Harvest time

Spear quality

To Cite : Köklü Ş, Dolunbay S, Yakupoğlu G, Karaca A, Havan A, Korkmaz A 2020. Bitki Yaşı ve Hasat Zamanının Kuşkonmaz Verimi ve Sürgün Kalitesi Üzerine Etkileri. KSÜ Tarım ve Doğa Derg 23 (3): 568-576. DOI: 10.18016/ksutarimdoga.vi.629335. 


\section{GİRİŞ}

Kuşkonmaz (Asparagus officinalis L.), Asparagaceae familyasının bir üyesi olup iki evcikli, otsu ve çok yıllık bir sebzedir. Beyaz ve yeşil sürgünleri taze pazarlanabildiği gibi konserve ve dondurulmuş olarak işlendikten sonra da tüketilmektedir. Batı ülkelerinde ve $A B D$ 'de çok değer verilen ve pahalı bir sebze olan kuşkonmazın anavatanı yurdumuzun da içinde bulunduğu Doğu Akdeniz olmasina rağmen halkımızca iyi tanınmadığı için ülkemizde önemli miktarlarda üretilip tüketilen bir sebze değildir (Eşiyok, 2012). İzmir ve çevresinde, Aydın, Muğla ve Manisa'da yabani formları bulunmakta ve ilkbaharda doğadan toplanarak sebze olarak değerlendirilmektedir.

Kuşkonmaz iklim istekleri bakımından seçici bir sebze değildir. Afrika'dan Kuzey Avrupa ülkelerine kadar geniş bir coğrafyada başarıyla üretilmektedir. Toprak ve hava sıcaklığı tomurcuk patlaması ve sürgün gelişimi için kritik bir role sahiptir. Tomurcuk patlaması için gerekli olan toprak sıcaklığı $5{ }^{\circ} \mathrm{C}$ iken sürgün çıkışı için toprak sicaklığının $13-14{ }^{\circ} \mathrm{C}$ 'ye ulaşması gerekmektedir (Dufault, 1994). Kuşkonmazda verim, bir önceki yıl köklerde biriken karbonhidrata bağlıdır (Gasecka vd., 2009; Krzsenski vd., 2008) ve köklerde çoğunlukla fruktoz (toplam depolanan karbonhidratların \%50-90) biriktirilir (Shiomi, 1992; Drost, 1997). Kuşkonmazda hasat periyodunun uzun tutulması yıllık sürgün verimini artırırken bir sonraki yılın verimini ve bitki ömrünü olumsuz etkilemektedir (Shelton ve Lacy, 1980; Williams ve Garthwaite, 1973). Hasadın sona ermesinden sonra gelişen sürgünler büyüyerek toprak üstü yeşil aksamı oluşturur. Bitkinin hayatta kalması ve sonraki yıllarda yüksek verim alınabilmesi için hasat süresi ile bitki aksamının gelişimi arasındaki dengenin iyi bir şekilde kurulması gerekmektedir. $\mathrm{Bu}$ denge, bitki büyüklüğüne, yaşına, hasat süresinin uzunluğuna, bitkinin içinde bulunduğu büyüme mevsiminin uzunluğuna ve bitki büyümesini sınırlayan çevresel faktörlere bağlıdır (Bohowmik ve Matsui, 2003; Robb, 1984).

Kuşkonmazda hasat genelde fide dikiminden sonra 3. yılda başlar (Dufault, 1994; Akan, 2014) ve bakım koşulları ve hasat döneminin uzunluğuna göre değişmekle birlikte 12-15 yıl sürebilir (Alan, 2017). Dikimden 1 yıl sonra (2. yıl) yapılan hasadın bazı kaynaklarda sürgün sayısı, sürgün çapı ve dolayısıyla toplam verimi olumsuz yönde etkilediği belirtilmiştir (Lloyd ve McCollum, 1938). Buna karşılık bazı araştırıcılar dikimden 1 yıl sonra yapılan hasadın verim ve kalitede herhangi bir olumsuz etkiye yol açmadığını bildirmişlerdir (Dufault, 1994; Benson ve Motes, 1982).

Kuşkonmaz hava sicaklıklarına bağlı olarak Kuzey yarım kürede, erken ilkbaharda (Ocak sonu-Şubat başı) hasat edilmeye başlar. Hasat bitki yaşına bağlı olarak 2-8 hafta sürer ve hasat sona erdikten sonra taze kuşkonmaz ihtiyacı farklı bölgelerden ya da farklı ülkelerden (özellikle güney yarıkürede yer alan) temin edilmeye çalışılır. Bu sebeple kuşkonmaz yetiştiriciliği yaygın şekilde yapılan ülkelerde kuşkonmazı yazın hasat etme fikri doğmuş ve bu yönde çalışmalar yapılmıştır. Yazın kuşkonmazı hasat etmek için toprak üstü aksamının biçilerek bitkileri yeniden sürmeye zorlanması gerekmektedir. Bitkileri yazın hasada zorlamak özellikle yetiştirme periyodunun uzun olduğu güney bölgelerde mümkündür. Bazı araştırmalarda yazın yapılan hasadın kalın sürgün sayısını arttırdığı ifade edilmesine rağmen bazıları da baharda yapılan hasatlara kıyasla sürgün kalitesini olumsuz etkilediği ve bu durumun köklerdeki karbonhidrat birikiminin yetersizliğinden kaynaklandığ Ayrıca, ilkbahar ve yaz olmak üzere yılda iki kez yapılan hasadın, kış dinlenmesinden önce karbonhidrat rezervlerini doldurmak için gereken zamanı azalttığı belirtilmiştir (Brasher, 1956).

Ülkemizde kuşkonmaz tüketimi yabanilerin toplanması ve tüketime sunulması ile sınırlı kalmış ve yetiştiriciliği bir kaç küçük çaplı deneme haricinde maalesef yaygınlaşamamıştır. Ayrıca, kuşkonmazda hem ilk hasada başlama yaşı hem de klasik bahar hasadına alternatif olarak yaz hasadı üzerine bir çalışmaya rastlanmamıştır. Bu nedenle yürütülen bu çalışmada farklı hasada başlama yaşı (2 ve 3 yaşında) ile farklı zamanlarda (bahar ve yaz aylarında) yapılan hasadın kuşkonmaz verimi ve sürgün kalitesi üzerine uzun dönem etkilerini belirleyerek Türkiye kuşkonmaz yetiştiriciliği ve üretimine katkı sağlamak amaçlanmıştır.

\section{MATERYAL ve YÖNTEM}

\section{Materyal}

Araştırma, Kahramanmaraş Sütçü İmam Üniversitesi Ziraat Fakültesi Bahçe Bitkileri Bölümü uygulama bahçesi ile Tohum ve Sebze Fizyolojisi laboratuvarında 2011-2016 tarihleri arasında yürütülmüştür. Araştırmada ‘UC 157' $F_{1}$ kuşkonmaz çeşidi materyal olarak kullanılmıştır.

\section{Yöntem}

Yetiştiricilik öncesinde arazinin toprak özellikleri hakkında bilgi edinebilmek amaciyla $30 \mathrm{~cm}$ derinlikte deneme parselinin 4 farklı yerinden alınmış toprak örnekleri üzerinde Kahramanmaraş Sütçü İmam Üniversitesi Ziraat Fakültesi Toprak Bilimi ve Bitki Besleme Bölümü'ne ait laboratuvarda fiziksel ve kimyasal analizler yaptırılmıştır. Toprak analiz sonuçlarına göre deneme arazisinin topraklarının killi-tınlı bünyeye sahip olduğu ve $\mathrm{pH}$ değerinin ise 7.8 olduğu belirlenmiştir. Ayrıca deneme arazisi 
toprağının organik madde içeriği $\% 0.64$, tuz miktarı $\% 0.12$, kireç miktarı \%17.1 fosfor miktarının $7.65 \mathrm{mg}$ $\mathrm{kg}^{-1}$ ve potasyum miktarı da $255.5 \mathrm{mg} \mathrm{kg}{ }^{-1}$ olarak belirlenmiştir.

Kuşkonmaz tohumları 2011 ile 2012 yıllarının Mart ayında viyollere ekilmiş ve elde edilen fideler daha iyi gelişmeleri için 4 hafta sonra serada saksılara aktarılmıştır. On haftalık fideler, Nisanın son haftasında araştırma parseline sıra arası $140 \mathrm{~cm}$ ve sıra üzeri $50 \mathrm{~cm}$ olacak şekilde dikilmiştir. Arazi dikim öncesi ve takip eden yıllarda, kış aylarında (AralıkOcak) 15:15:15 NPK gübresi (80 $\left.\mathrm{kg} \mathrm{da}^{-1}\right)$ ile gübrelenmiştir. Bitkiler damla sulama ile sulanmış ve vejetasyon döneminde üç kez 20:20:20+iz element gübresi (25 kg da-1) ile gübrelenmiştir (Drost, 2013). Kuşkonmazlara herhangi bir pestisit uygulanmamış olup yabancı otla mücadele elle veya çapalama yapmak suretiyle sağlanmıştır. Sonbaharda (Ekim sonu-Kasım başı) yapraklarının sararmaya başlamasıyla birlikte bitkiler toprak üzerinden biçilmiş ve kış dinlenmesine bırakılmıştır. Deneme iki farklı hasada başlama yaşı ( 2 ve 3 yaş) ve iki farklı hasat zamaninin (bahar ve yaz) verime olan etkisini araştırmak üzere faktöriyel deneme desenine göre kurulmuştur. Her bir uygulama üç kez yinelenmiş ve her tekerrürde 15 ile 20 arasında değişen sayıda bitki yer almıştır.

Bitkilerin hasadına 2014 yılından itibaren başlanılmıştır; 2012 yılında dikilen kuşkonmazlar ilk kez 2 yaşında hasat edilirken, 2011 yılında dikilmiş olan kuşkonmazlar ise 3 yaşında hasat edilmiştir. Baharda bitkiler toprak sıcaklığına göre değişmekle birlikte 2014 yılında 18 Mart-18 Nisan, 2015 yılında 28 Mart-28 Nisan ve 2016 yllında ise 21 Mart-22 Nisan tarihlerinde tarihleri arasında her gün hasat edilmiştir. Yazın hasat edilen bitkilerde baharda hasat yapılmadan sürgünler büyümeye bırakılmıştır. Mayıs ayının son haftasında bitkiler toprak seviyesinden biçilerek sürmeye zorlanmıştır. Her 3 yılda da 1-30 Haziran tarihleri arasında bitkiler hasat edilmiştir. Hasat edilen tüm sürgünlerin uzunlukları ve kalınlıkları (sürgünlerin dip kısımlarının çapları) dijital kumpasla belirlenmiş ve daha sonra sürgünler kalınlıklarına göre sınıflandırılmıştır. Öncelikle herhangi bir şekil bozukluğu olmayan ve sürgün çapı

8 mm'den büyük olan sürgünler pazarlanabilir olarak belirlenmiş ve kendi aralarında çaplarına göre 3 farklı gruba (8-12 mm-ince, $12-16 \mathrm{~mm}$-orta ve $>16 \mathrm{~mm}$ jumbo) ayrılmıştır. Sürgün çapı $8 \mathrm{~mm}$ 'den küçük olanlar (çok ince) ile şekilsiz ve açılmış olan sürgünler ise pazarlanamaz olarak kaydedilmiştir

Kuşkonmazda farklı yaştaki bitkilerde farklı zamanlarda yapılan hasadın köklerde ağırlıklı olarak

depolanan bir karbonhidrat türü olan fruktoz içeriği üzerine etkileri belirlenmiştir.

Kuşkonmazda farklı yaştaki bitkilerde farklı zamanlarda yapılan hasadın köklerde ağırlıklı olarak depolanan bir karbonhidrat türü olan fruktoz içeriği üzerine etkileri belirlenmiştir. Bunun için 5 farklı zamanda (bahar hasadı başında, bahar hasadı sonunda, yaz hasadı başında, yaz hasadı sonunda ve sonbaharda bitkiler biçildiğinde) her bir uygulamanın her bir tekerrüründen rasgele seçilmiş bitkilerden kök örnekleri alınmıştır. Alınan kök örnekleri iyice yıkanmış, etüvde $70{ }^{\circ} \mathrm{C}$ ' de 72 saat boyunca kurutulmuş ve sonrasında değirmen yardımıyla öğütülmüştür. Kurutulmuş ve öğütülmüş kök örneklerinde karbonhidrat içeriğinin belirlenmesi Morris (1948)'in metoduna göre yapılmıştır. Araştırma sonucu elde edilen veriler, hasat yapılan her bir yıl için ayrı olarak SAS istatistik paket programı kullanarak iki faktörlü olarak varyans analizine tabi tutulmuştur. Ana faktör ve önemli olması durumunda interaksiyon ortalamaları arasındaki farklılıkların belirlenmesinde LSD (asgari önemli fark) testi kullanılmıştır.

\section{BULGULAR}

Çizelge 1 ve 2 'de yıllara göre sunulan varyans analiz sonuçları incelendiğinde, bitki yaşının özellikle sürgün kalitesi ve bitki başına düşen sürgün sayısı üzerine istatiksel anlamda önemli bir etkisinin olduğu, hasat zamanının sürgün sayısı ve sürgün kalitesini etkileyen özelliklerin neredeyse tamamı üzerinde önemli bir etkisinin bulunduğu belirlenmiştir. Yine Çizelge 1 ve 2 incelendiğinde ikili interaksiyon (BY x HZ) etkisinin 2014 yılında elde edilen sürgünlerin ortalama çap değerleri hariç istatiksel anlamda bir farklılık meydana getirmediği görülmektedir.

Hasada başlama yaşı ve farklı zamanlarda yapılan hasadın bitki başına düşen pazarlanabilir sürgün sayısı, ortalama sürgün çapı ve boyu üzerine olan etkileri Çizelge 3'de sunulmuştur. Yıllara göre elde edilen veriler incelendiğinde hasada başlama yaşının bitki başına düşen sürgün sayısı üzerine önemli bir etkisinin olduğu görülmüş ve yaşa bağlı olarak sürgün sayısında önemli artışlar meydana gelmiştir. Özellikle 3 yaşında hasada başlanan bitkilerde hasadın ilk yılı olan 2014 yılında 8.4 adet olan bitki başına düşen sürgün veriminin 2015 yılında 13.76 olduğu 2016 yılına gelindiğinde ise artarak 18.67'lere çıktığı belirlenmiştir. Üç yaşında hasada başlama zamanı, iki yaşında hasada başlama zamanı ile kıyaslandığında 2014 yılında \%140, 2015 yılında \%79 ve 2016 yilında ise \%74'lük oranda bitki başına sürgün sayısında artış sağlamıştır. Hasat zamanının ilk hasat yılı olan 2014 yılında önemli bir etkisinin olmadığı görülmüş fakat takip eden yıllarda baharda yapılan hasatlardan yazın yapılan hasatlara kıyasla \%58-\%98 arasında değişen oranlarda bitki başına daha fazla sayıda pazarlanabilir sürgün elde edilmiştir.

Ortalama sürgün çapı üzerine, hasadın ilk iki yılında hasada başlama yaşının önemli bir etkisi gözlemlenmemiş, fakat 2016 yılında istatiksel olarak 
Çizelge 1. Farklı yaşlarda ve zamanlarda hasat edilen pazarlanabilir kuşkonmaz sürgünlerinin sayısı, çapı ve uzunluğuna ait varyans analiz tablosu

Table 1. Asparagus marketable spear yield as influenced by plant age and harvest time

\begin{tabular}{|c|c|c|c|c|c|c|c|c|c|}
\hline & \multicolumn{3}{|c|}{$\begin{array}{l}\text { Sürgün/bitki (adet) } \\
\text { (spear/plant) }\end{array}$} & \multicolumn{3}{|c|}{$\begin{array}{l}\text { Ortalama çap }(\mathrm{mm}) \\
\text { (Spear diameter) }\end{array}$} & \multicolumn{3}{|c|}{$\begin{array}{l}\text { Ortalama boy }(\mathrm{cm}) \\
\text { (Spear length) }\end{array}$} \\
\hline $\begin{array}{l}\text { Uygulamalar } \\
\text { (Treatments) }\end{array}$ & 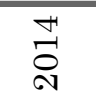 & $\stackrel{10}{\stackrel{2}{8}}$ & $\begin{array}{l}0 \\
\stackrel{\sim}{0} \\
\stackrel{\text { }}{1}\end{array}$ & 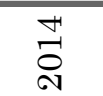 & $\stackrel{10}{\underset{8}{1}}$ & $\begin{array}{l}0 \\
\stackrel{\sim}{\sim} \\
\text { }\end{array}$ & $\underset{\text { H }}{\stackrel{\text { d }}{2}}$ & 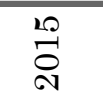 & $\begin{array}{l}0 \\
\stackrel{1}{0} \\
\text { N }\end{array}$ \\
\hline $\begin{array}{l}\text { Bitki yaşı (BY) } \\
\text { (Plant age- } P A)\end{array}$ & $* * *$ & $* *$ & * & $\begin{array}{l}\text { ÖD } \\
(N S)\end{array}$ & $\begin{array}{l}\text { ÖD } \\
(N S)\end{array}$ & $*$ & $\begin{array}{l}\text { ÖD } \\
(N S)\end{array}$ & $\begin{array}{l}\text { ÖD } \\
(N S)\end{array}$ & $\begin{array}{l}\text { ÖD } \\
(N S)\end{array}$ \\
\hline $\begin{array}{l}\text { Hasat zamanı }(\mathrm{HZ}) \\
\text { (Harvest time-HT) }\end{array}$ & ÖD & $* *$ & * & $* *$ & $* * *$ & $* * *$ & ÖD & ÖD & $* * *$ \\
\hline $\begin{array}{l}\mathrm{BY} \times \mathrm{HZ} \\
(P A \times H T)\end{array}$ & $\begin{array}{l}\text { ÖD } \\
(N S)\end{array}$ & $\begin{array}{l}\text { ÖD } \\
(N S)\end{array}$ & $\begin{array}{l}\text { ÖD } \\
(N S)\end{array}$ & $* *$ & $\begin{array}{l}\text { ÖD } \\
(N S)\end{array}$ & $\begin{array}{l}\text { ÖD } \\
(N S)\end{array}$ & $\begin{array}{l}\text { ÖD } \\
(N S)\end{array}$ & $\begin{array}{l}\text { ÖD } \\
(N S)\end{array}$ & $\begin{array}{l}\text { ÖD } \\
(N S)\end{array}$ \\
\hline
\end{tabular}

$* * *: p \leq 0.001, * *: p<0.01, *: p<0,05$, ÖD: önemli değil. NS: not significant

Çizelge 2. Farklı yaşlarda ve zamanlarda hasat edilen pazarlanabilir kuşkonmaz sürgünlerinin kalite özelliklerine ait varyans analiz tablosu

Table 2. Asparagus marketable spear quality characteristics as influenced by plant age and harvest time

\begin{tabular}{|c|c|c|c|c|c|c|c|c|c|}
\hline \multirow[b]{2}{*}{$\begin{array}{l}\text { Uygulamalar } \\
\text { (Treatments) }\end{array}$} & \multicolumn{3}{|c|}{$\begin{array}{c}8-12 \mathrm{~mm} \\
\text { sürgün/bitki } \\
\text { (8-12 } \mathrm{mm} \text { spear/plant) }\end{array}$} & \multicolumn{3}{|c|}{$\begin{array}{c}12-16 \mathrm{~mm} \\
\text { sürgün/bitki } \\
(12-16 \mathrm{~mm} \text { spear/plant) }\end{array}$} & \multicolumn{3}{|c|}{$\begin{array}{c}>16 \mathrm{~mm} \\
\text { sürgün/bitki } \\
\text { (>16 mm spear/plant) }\end{array}$} \\
\hline & 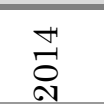 & $\begin{array}{l}20 \\
\stackrel{4}{\circ}\end{array}$ & $\begin{array}{l}0 \\
\stackrel{\sim}{*}\end{array}$ & $\underset{⿱}{\stackrel{4}{ }}$ & 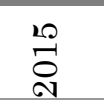 & $\begin{array}{l}0 \\
\stackrel{\sim}{\sim} \\
\stackrel{\sim}{1}\end{array}$ & $\underset{\sim}{\stackrel{4}{*}}$ & 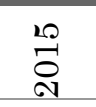 & $\begin{array}{l}0 \\
\stackrel{1}{0} \\
\stackrel{N}{N}\end{array}$ \\
\hline $\begin{array}{l}\text { Bitki yaşı }(\mathrm{BY}) \\
\text { (Plant age- } P A)\end{array}$ & $* *$ & * & * & $* *$ & * & * & $* * *$ & $* *$ & $\begin{array}{l}\text { ÖD } \\
(N S)\end{array}$ \\
\hline $\begin{array}{l}\text { Hasat zamanı }(\mathrm{HZ}) \\
\text { (Harvest time-HT) }\end{array}$ & $* *$ & ÖD & $* *$ & ÖD & $* *$ & ÖD & $* *$ & $* * *$ & $* * *$ \\
\hline $\begin{array}{l}\mathrm{BY} \times \mathrm{HZ} \\
(P A \times H T)\end{array}$ & $\begin{array}{l}\text { ÖD } \\
(N S)\end{array}$ & $\begin{array}{l}\text { ÖD } \\
(N S)\end{array}$ & $\begin{array}{l}\text { ÖD } \\
(N S)\end{array}$ & $\begin{array}{l}\text { ÖD } \\
(N S)\end{array}$ & $\begin{array}{l}\text { ÖD } \\
(N S)\end{array}$ & $\begin{array}{l}\text { ÖD } \\
(N S)\end{array}$ & $\begin{array}{l}\text { ÖD } \\
(N S)\end{array}$ & $\begin{array}{l}\text { ÖD } \\
(N S)\end{array}$ & $\begin{array}{l}\text { ÖD } \\
(N S)\end{array}$ \\
\hline
\end{tabular}

$* * *: \mathrm{p} \leq 0.001,{ }^{* *}: \mathrm{p}<0.01,{ }^{*}: \mathrm{p}<0,05$, ÖD: önemli değil. NS: not significant

Çizelge 3. Hasada başlama yaşı ve farklı zamanlarda yapılan hasadın bitki başına düşen pazarlanabilir sürgün sayısı, sürgün kalınlığı ve sürgün uzunluğu üzerine etkileri

Table 3. The effect of plant age and harvest time on number of marketable asparagus spears, spear diameter and spear length

\begin{tabular}{|c|c|c|c|c|}
\hline $\begin{array}{c}\text { Yil } \\
(\text { Year })\end{array}$ & $\begin{array}{l}\text { Uygulamalar } \\
\text { (Treatments) }\end{array}$ & $\begin{array}{l}\text { Sürgün/bitki (adet) } \\
\text { (Spear/plant) }\end{array}$ & $\begin{array}{l}\text { Ortalama çap }(\mathrm{mm}) \\
\text { (Spear diameter })\end{array}$ & $\begin{array}{l}\text { Ortalama boy (cm) } \\
\text { (Spear length) }\end{array}$ \\
\hline \multirow{4}{*}{ 孛 } & Bahar hasadı (Spring harvest) & $5.65 \pm 1.35$ & $12.15 \pm 0.19 \mathrm{a}$ & $25.19 \pm 0.22$ \\
\hline & Yaz hasadı (Summer harvest) & $6.22 \pm 1.17$ & $10.92 \pm 0.15 \mathrm{~b}$ & $26.13 \pm 0.37$ \\
\hline & 2 yaş (2 years old) & $3.50 \pm 0.43 \mathrm{~b}$ & $11.47 \pm 0.15$ & $25.71 \pm 0.34$ \\
\hline & 3 yaş (3 years old) & $8.40 \pm 0.77 \mathrm{a}$ & $11.60 \pm 0.43$ & $25.60 \pm 0.40$ \\
\hline \multirow{4}{*}{$\stackrel{10}{\stackrel{2}{\circ}}$} & Bahar hasadı (Spring harvest) & $14.27 \pm 2.53 \mathrm{a}$ & $14.41 \pm 0.24 \mathrm{a}$ & $25.64 \pm 0.15$ \\
\hline & Yaz hasadı (Summer harvest) & $7.19 \pm 0.82 \mathrm{~b}$ & $11.98 \pm 0.20 \mathrm{~b}$ & $25.62 \pm 0.21$ \\
\hline & 2 yaş (2 years old) & $7.69 \pm 1.001 \mathrm{~b}$ & $13.45 \pm 0.50$ & $25.52 \pm 0.23$ \\
\hline & 3 yaş (3 years old) & $13.76 \pm 2.724 \mathrm{a}$ & $12.93 \pm 0.64$ & $25.73 \pm 0.112$ \\
\hline \multirow{4}{*}{$\begin{array}{l}0 \\
\stackrel{0}{\circ} \\
\stackrel{\text { v }}{1}\end{array}$} & Bahar hasadı (Spring harvest) & $17.99 \pm 3.75 \mathrm{a}$ & $15.85 \pm 0.44 \mathrm{a}$ & $24.17 \pm 0.15 \mathrm{~b}$ \\
\hline & Yaz hasadı (Summer harvest) & $11.40 \pm 0.70 \mathrm{~b}$ & $12.36 \pm 0.20 \mathrm{~b}$ & $26.25 \pm 0.11 \mathrm{a}$ \\
\hline & 2 yaş (2 years old) & $10.71 \pm 0.54 . \mathrm{b}$ & $14.59 \pm 0.61 \mathrm{a}$ & $25.26 \pm 0.53$ \\
\hline & 3 yaş (3 years old) & $18.67 \pm 3.50 \mathrm{a}$ & $13.62 \pm 0.72 \mathrm{~b}$ & $25.16 \pm 0.43$ \\
\hline
\end{tabular}

a, b, c; Sütün içerisinde aynı harf ile işaretlenmiş ortalamalar $\mathrm{P}<0.05$ seviyesinde istatistiksel olarak birbirinden farklı değildir. Means followed by the same letter within the column are not statistically different at $\mathrm{P}<0.05$ 
$(\mathrm{p}<0.05)$ bir etkiye sahip olmuş ve iki yaşında hasada başlanan bitkilerden elde edilen sürgünlerin ortalama çapı $(14.59 \mathrm{~mm}), 3$ yaşında hasada başlanan sürgünlerin ortalama çapına $(13.62 \mathrm{~mm})$ kıyasla daha yüksek bulunmuştur. Ayrıca hasat zamanının sürgün çapı üzerine tüm sezonlarda önemli bir etki yaptığı görülmüş ve baharda hasat edilen sürgünlerin kalınlığının yazın hasat edilenlere göre daha fazla olduğu belirlenmiştir. Hasada başlama yaşı ve hasat zamanı arasındaki interaksiyon ilişkisi ortalama sürgün çapı üzerinde araştırmanın ilk yılı olan 2014 senesinde önemli bulunmuş ve en kalın sürgünler $(12.60 \mathrm{~mm})$ ilk kez 3. yılda baharda hasat edilen bitkilerden, en ince sürgünler ise bitki yaşı fark etmeksizin yazın hasat edilen bitkilerden elde edilmiştir (Çizelge 4). Ortalama sürgün boyları üzerine bitki yaşının önemli bir etkisi belirlenmez iken, hasat zamanının etkisi 2016 yılında $(p<0.001)$ önemli bulunmuştur. Bu yılda yazın hasat edilen sürgünlerin boy ortalamasinın $(26.25 \mathrm{~cm})$, bahar hasatlarına $(24.17$ cm) kıyasla arttırdığı görülmüştür.

Hasada başlama yaşı ve hasat zamanının sürgünlerin kalitesinin dağılımı üzerine etkileri Çizelge 5'de sunulmuştur. Uygulamaların ince $(8-12 \mathrm{~mm})$ sürgünler üzerine etkisi incelendiğinde, hasada başlama yaşı tüm hasat sezonlarında sürgün sayısını önemli bir seviyede etkilediği ve ilk kez 3. yılda hasat edilen bitkilerden daha fazla sayıda ince sürgün elde edildiği bulunmuştur. Hasat zamanının etkisi ise 2015 yılı hariç tüm sezonlarda önemli bulunmuş ve yazın hasat edilen bitkilerden daha fazla sayıda ince sürgün hasat edilmiştir. Uygulamaların genelde pazarın en çok tercih ettiği orta kalınlıktaki $(12-16 \mathrm{~mm})$ sürgün sayısı üzerine olan etkileri değerlendirildiğinde, baharda yapılan hasatlardan yaz hasatlarına kıyasla daha fazla sayıda sürgün elde edilmesine rağmen hasat zamanının etkisi 2015 yılı hariç diğer yıllarda istatistiksel olarak önemsiz bulunmuştur. Ayrıca, ilk kez 3. yılda hasat edilen bitkilerden 2. yılda hasat edilenlere kıyasla her üç hasat sezonunda da daha fazla sayıda sürgün elde edilmiştir. Yine ilk kez 3. yılda hasat edilen bitkilerden 2. yılda hasat edilenlere kıyasla araştırmanın son yılı olan 2016 yılı hariç diğer iki hasat sezonunda da jumbo kalınlıkta daha fazla sayıda sürgün hasat edilmiştir. Buna karşılık hasat zamanı jumbo sürgün sayısı üzerinde her 3 yılda da etkili olmuş ve baharda hasat edilen bitkilerden yazın hasat edilenlere kıyasla daha fazla sayıda jumbo sürgün elde edilmiştir. Hasada başlama yaşı ve hasat zamanının 3 hasat sezonu boyunca bitki başına elde edilen pazarlanamaz sürgün sayısı üzerine tüm ylllarda önemli etkiye sahip olduğu olduğu görülmüştür (Çizelge 6 ve 7).

Çizelge 4. Hasada başlama yaşı ve hasat zamanın 2014 yılında elde edilen sürgünlerin kalınlığı üzerine etkileri Table 4. Interaction effect of plant age and harvest time on spear diameter in 2014

Hasada Başlama Yaşı (Plant age at first harvest)

\begin{tabular}{|c|c|c|c|}
\hline Hasat Zamanı (Harvest time) & 2 yaş (2 years old) & 3 yaş (3 years old) & Ortalama (Mean) \\
\hline Bahar (Spring) & $11.80 \pm 0.1 \mathrm{~b}$ & $12.60 \pm 0.1 \mathrm{a}$ & $12.15 \pm 0.2 \mathrm{a}$ \\
\hline Yaz (Summer) & $11.10 \pm 0.1 \mathrm{bc}$ & $10.60 \pm 0.2 \mathrm{c}$ & $10.90 \pm 0.2 \mathrm{~b}$ \\
\hline Ortalama (Mean) & $11.47 \pm 0.2$ & $11.60 \pm 0.4$ & \\
\hline
\end{tabular}

a, b, c; Sütün içerisinde aynı harf ile işaretlenmiş ortalamalar $\mathrm{P}<0.05$ seviyesinde istatistiksel olarak birbirinden farklı değildir.

Means followed by the same letter within the column are not statistically different at $\mathrm{P}<0.05$

Çizelge 5. Hasada başlama yaşı ve hasat zamanının sürgün kalitesinin dağılımı üzerine etkileri

Table 5. The effect of plant age and harvest time on marketable spear quality

\begin{tabular}{|c|c|c|c|c|}
\hline $\begin{array}{c}\text { Yil } \\
\text { (Year) }\end{array}$ & $\begin{array}{l}\text { Uygulamalar } \\
\text { (Treatments) }\end{array}$ & $\begin{array}{l}\text { 8-12 mm sürgün/bitki } \\
(8-12 \mathrm{~mm} \text { spear/plant) }\end{array}$ & $\begin{array}{l}\text { 12-16 mmsürgün/bitki } \\
\text { (12-16 mm spear/plant) }\end{array}$ & $\begin{array}{l}>16 \mathrm{~mm} \text { sürgün/bitki } \\
\text { (>16 mm spear/plant) }\end{array}$ \\
\hline \multirow{4}{*}{$\underset{\vec{N}}{\vec{N}}$} & Bahar hasadı (Spring harvest) & $2.98 \pm 0.62 \mathrm{~b}$ & $2.03 \pm 0.55$ & $0.64 \pm 0.21 \mathrm{a}$ \\
\hline & Yaz hasadı (Summer harvest) & $4.39 \pm 0.87 \mathrm{a}$ & $1.63 \pm 0.34$ & $0.20 \pm 0.04 \mathrm{~b}$ \\
\hline & 2 yaş (2 years old) & $2.24 \pm 0.30 \mathrm{~b}$ & $1.05 \pm 0.14 \mathrm{~b}$ & $0.18 \pm 0.04 \mathrm{a}$ \\
\hline & 3 yaş (3 years old) & $5.13 \pm 0.65 \mathrm{a}$ & $2.62 \pm 0.40 \mathrm{a}$ & $0.66 \pm 0.20 \mathrm{~b}$ \\
\hline \multirow{4}{*}{$\stackrel{20}{\stackrel{2}{2}}$} & Bahar hasadı (Spring harvest) & $3.40 \pm 1.43$ & $5.42 \pm 0.81 \mathrm{a}$ & $5.42 \pm 0.81 \mathrm{a}$ \\
\hline & Yaz hasadı (Summer harvest) & $3.90 \pm 0.54$ & $2.56 \pm 0.33 \mathrm{~b}$ & $2.56 \pm 0.33 \mathrm{~b}$ \\
\hline & 2 yaş (2 years old) & $2.65 \pm 0.22 \mathrm{~b}$ & $4.20 \pm 0.48 \mathrm{~b}$ & $3.01 \pm 0.88 \mathrm{a}$ \\
\hline & 3 yaş (3 years old) & $5.47 \pm 1.15 \mathrm{a}$ & $7.15 \pm 0.90 \mathrm{a}$ & $4.96 \pm 0.98 \mathrm{~b}$ \\
\hline \multirow{4}{*}{ 节 } & Bahar hasadı (Spring harvest) & $1.84 \pm 0.69 \mathrm{~b}$ & $6.74 \pm 1.43$ & $8.04 \pm 1.21 \mathrm{a}$ \\
\hline & Yaz hasadı (Summer harvest) & $5.41 \pm 0.51 \mathrm{a}$ & $4.60 \pm 0.28$ & $1.38 \pm 1.36 \mathrm{~b}$ \\
\hline & 2 yaş (2 years old) & $2.75 \pm 0.73 \mathrm{~b}$ & $3.01 \pm 0.40 \mathrm{~b}$ & $3.76 \pm 1.10$ \\
\hline & 3 yaş (3 years old) & $4.50 \pm 1.09 \mathrm{a}$ & $4.96 \pm 0.91 \mathrm{a}$ & $5.66 \pm 2.08$ \\
\hline
\end{tabular}

a, b, c; Sütün içerisinde aynı harf ile işaretlenmiş ortalamalar $\mathrm{P}<0.05$ seviyesinde istatistiksel olarak birbirinden farklı değildir. Means followed by the same letter within the column are not statistically different at $\mathrm{P}<0.05$ 
Çizelge 6. Farklı yaşlarda ve zamanlarda hasat edilen pazarlanamaz kuşkonmaz sürgünlerinin bitki başına düşen sürgün sayisına ait varyans analiz tablosu

Table 6. Asparagus cull spear yield as influenced by plant age and harvest time

\begin{tabular}{|lc|c|c|}
\hline & \multicolumn{3}{c|}{ Sürgün/bitki (adet) (spear/plant) } \\
\hline Uygulamalar (Treatments) & 2014 & 2015 & 2016 \\
\hline Bitki yaşı (BY) (Plant age-PA) & $* * *$ & $* * *$ & $*$ \\
\hline Hasat zamanı (HZ) (Harvest time-HT) & $* * *$ & $*$ & $* *$ \\
\hline BY x HZ (PA $\times$ HT) & $*$ & ÖD (NS) & ÖD (NS) \\
\hline
\end{tabular}

$* * *: p \leq 0.001, * *: p<0.01, *: p<0,05$, ÖD: önemli değil. NS: not significant

Çizelge 7. Farklı yaşlarda ve farklı zamanlarda yapılan hasadın bitki başına düşen pazarlanamaz sürgün sayısı üzerine olan etkileri

Table 7. The effect of plant age and harvest time on number of cull asparagus spears

\begin{tabular}{|l|c|c|c|}
\hline & \multicolumn{3}{|c|}{ Hasada Başlama Yaşı (Plant age at first harvest) } \\
\hline Hasat Zamanı (Harvest time) & 2 yaş (2 years old) & 2 yaş (2 years old) & Ortalama (Mean) \\
\hline Bahar (Spring) & $1.1 \pm 0.1 \mathrm{c}$ & $2.1 \pm 0.5 \mathrm{bc}$ & $1.6 \pm 0.3 \mathrm{~b}$ \\
\hline Yaz (Summer) & $3.2 \pm 0.3 \mathrm{~b}$ & $6.4 \pm 0.4 \mathrm{a}$ & $4.8 \pm 0.8 \mathrm{a}$ \\
\hline Ortalama (Mean) & $2.2 \pm 0.5 \mathrm{~b}$ & $4.3 \pm 1.0 \mathrm{a}$ & \\
\hline
\end{tabular}

a, b, c; Aynı harf ile işaretlenmiş ortalamalar $\mathrm{P}<0.05$ seviyesinde istatistiksel olarak birbirinden farklı değildir. Means followed by the same letter are not statistically different at $\mathrm{P}<0.05$

Çizelge 6 ve 7 'deki sonuçlar detaylı incelendiğinde yazın hasat yapılan bitkilerden baharda hasat edilenlere kıyasla, ayrıca dikimden sonra 3. sene ilk kez hasat yapılan bitkilerden de dikimi takip eden yıl hasadı yapılanlara kıyasla daha fazla sayıda pazarlanamaz sürgün elde edildiği görülmüştür.
Ayrıca hasadın ilk yılı olan 2014 sezonunda uygulamalar arasındaki interaksiyon ilişkisi önemli bulunmuş ve en fazla sayıda pazarlanamaz sürgün, dikimi takiben 3 . senenin yazında hasat edilen bitkilerden elde edilirken en az sayıda pazarlanamaz sürgün ise dikimi takip eden senenin baharında hasat edilen bitkilerden elde edilmiştir (Çizelge 8).

Çizelge 8. Hasada başlama yaşı ve hasat zamanının 2014 yılında bitki başına düşen pazarlanamaz sürgün sayısı üzerine etkileri

Table 8. Interaction effect of plant age and harvest time on number of cull spears in 2014

\begin{tabular}{|c|c|c|}
\hline Yll (Year) & Uygulamalar (Treatments) & Sürgün/bitki (adet) (spear/plant) \\
\hline \multirow{4}{*}{ 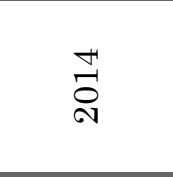 } & Bahar hasadı (Spring harvest) & $1.61 \pm 0.31 \mathrm{~b}$ \\
\hline & Yaz hasadı (Summer harvest) & $4.82 \pm 0.75 \mathrm{a}$ \\
\hline & 2 yaş (2 years old) & $2.17 \pm 0.50 \mathrm{~b}$ \\
\hline & 3 yaş (3 years old) & $4.26 \pm 1.01 \mathrm{a}$ \\
\hline \multirow{4}{*}{$\stackrel{10}{\stackrel{2}{\circ}}$} & Bahar hasadı (Spring harvest) & $2.89 \pm 0.90 \mathrm{~b}$ \\
\hline & Yaz hasadı (Summer harvest) & $4.79 \pm 0.75 \mathrm{a}$ \\
\hline & 2 yaş (2 years old) & $2.47 \pm 0.38 \mathrm{~b}$ \\
\hline & 3 yaş (3 years old) & $5.21 \pm 0.89 \mathrm{a}$ \\
\hline \multirow{4}{*}{$\begin{array}{l}0 \\
\stackrel{1}{\circ} \\
\text { م }\end{array}$} & Bahar hasadı (Spring harvest) & $2.93 \pm 1.08 \mathrm{~b}$ \\
\hline & Yaz hasadı (Summer harvest) & $5.68 \pm 1.09 \mathrm{a}$ \\
\hline & 2 yaş (2 years old) & $2.45 \pm 0.64 \mathrm{~b}$ \\
\hline & 3 yaş (3 years old) & $6.16 \pm 1.15 \mathrm{a}$ \\
\hline
\end{tabular}

a, b, ; Aynı harf ile işaretlenmiş ortalamalar $\mathrm{P}<0.05$ seviyesinde istatistiksel olarak birbirinden farklı değildir. Means followed by the same letter are not statistically different at $\mathrm{P}<0.05$

Hasada başlama yaşı ve farklı zamanlarda yapılan hasadın kuşkonmaz köklerinde depolanan karbonhidrat içeriğindeki değişimler incelendiğinde her üç yılda da uygulamalar arasında karbonhidrat içeriği yönünden çok ciddi farklılıkların oluşmadığg görülmüştür (Şekil 1). Kış dinlenmesi sonrası bahar hasadı öncesinde tüm bitkilerin benzer karbonhidrat içeriğine sahip oldukları gözlemlenmiş ve doğal olarak sürgünlerin gelişmesi ve 1 ay süren hasat sonrasında hasat yapılan bitkiler, hasat yapılmayan bitkilere kıyasla daha düşük miktarlarda karbonhidrat biriktirmişlerdir. Hasadın bitmesi sonrasında fotosentez yapan sürgünlerin gelişmesiyle bitkilerin köklerinde depolanan karbonhidrat içeriğinde artış gözlemlenmiş ancak yazın hasat edilen bitkilerde karbonhidrat içeriği yine önemli seviyede azalmıştır. 

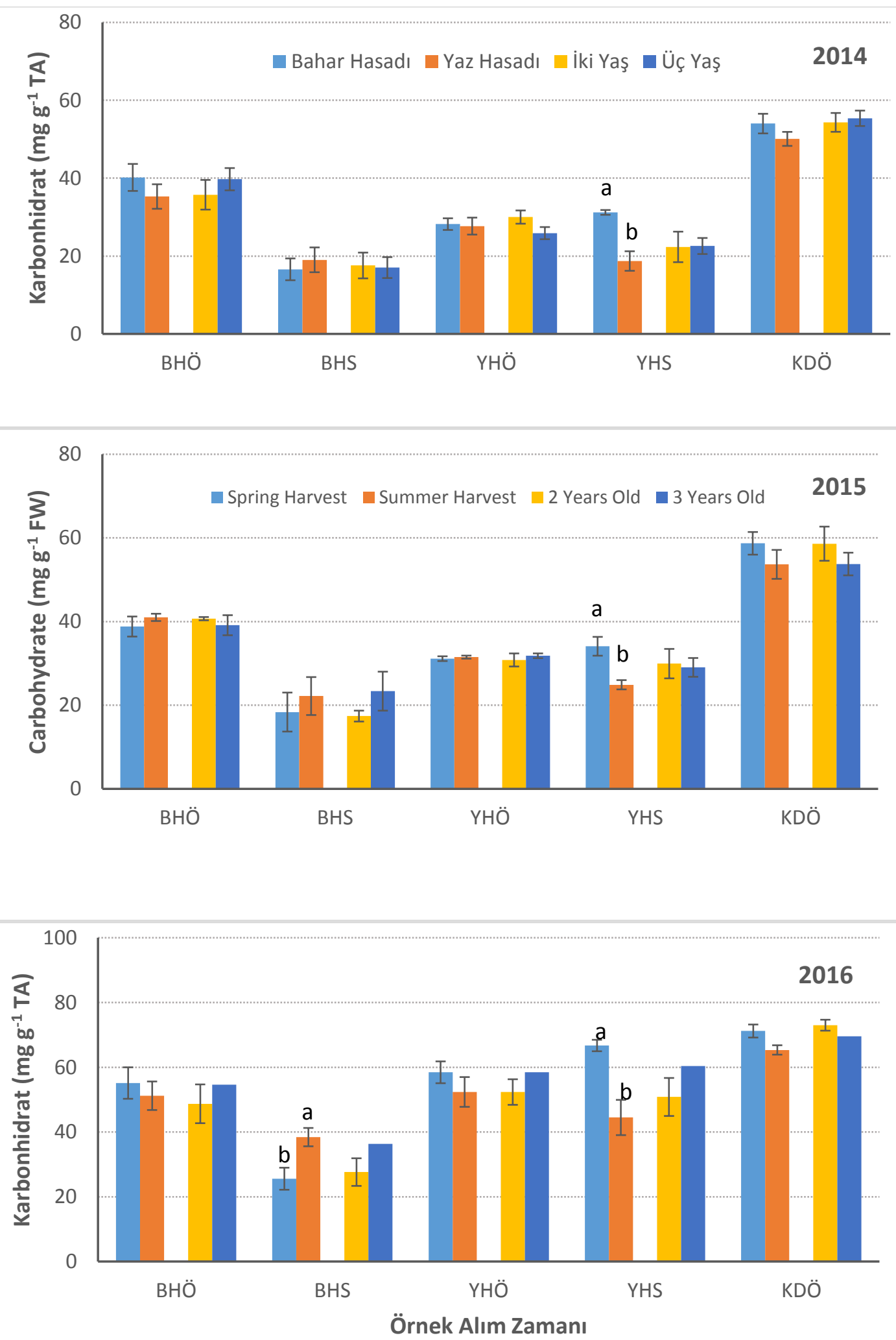

Şekil 1. Üç hasat sezonu boyunca kuşkonmaz köklerinin karbonhidrat içeriğindeki değişimler. BHÖ: Bahar hasadı öncesi. BHS: Bahar hasadı sonrası. YHÖ: Yaz hasadı öncesi. YHS: Yaz hasadı sonrası ve KDÖ: Kış dinlenmesi öncesi

Figure 1. Variations in carbohydrate status in asparagus roots over 3 harvest seasons. BHÖ: Before spring harvest. BHS: After spring harvest. YHÖ: Before summer harvest. YHS: After summer harvest. KDÖ: Before winter rest 
Yaz hasadın sonlanmasıyla birlikte sürgünlerin gelişmesi sonucu tüm bitkilerde karbonhidrat içeriği artarak kış dinlenmesi öncesinde sezon öncesi değerlerin üzerine çıkmıştır.

Bitkilerin köklerindeki karbonhidrat içeriğinde kış dinlenmesi sırasında bir miktar düşüş yaşanmış, ancak takip eden sene hasat öncesinde tüm uygulamalardaki bitkilerin benzer seviyelerde karbonhidrata sahip oldukları görülmüştür. Ayrıca, hasada başlama yaşının tüm hasat sezonlarında köklerde biriktirilen karbonhidrat içeriğine kayda değer bir etkisinin olmadığı bulunmuştur.

\section{TARTISSMA}

Kuşkonmazda hasadın genellikle fide dikiminden sonra üçüncü yılda başladığı ve bakım koşulları ile hasat döneminin uzunluğuna göre değişmekle birlikte 10 yıldan fazla sürdüğü daha önce ifade edilmişti. Ancak Wien (1997) kuşkonmaz hasadının verim, kalite ve bitki ömrü gibi kriterler dikkate alındığında ciddi kayıplara neden olmadan 2. yıldan itibaren yapılabileceğini vurgulamıştır. Kuşkonmazda hasat periyodunun uzun tutulması ylllı hasat verimini

artırırken bir sonraki yılın verimini. sürgün kalitesini ve bitki ömrünü de olumsuz etkilemektedir (Shelton ve Lacy, 1980; Takatori vd., 1970; Williams ve Garthwaite, 1973). Bu nedenle bitkileri uzun süre kuvvetli tutabilmek için dikim yılı ve sonraki yıl hasat yapılması genelde önerilmez. Dikimden 1 yıl sonra (2. yıl) yapılan hasadın bazı kaynaklarda (Lloyd ve McCollum, 1938) sürgün sayısını ve kalitesini olumsuz yönde etkilediği belirtilmiş olsa da bazı araştırıcılar sürgün sayısını etkilemediğini fakat sürgün kalınlığı ve ağırlığının azaldığını bildirmişlerdir (Krzesinky vd., 2008). Buna karşllık dikimden 1 yıl sonra yapılan hasadın verim ve kalitede herhangi bir olumsuz etkiye yol açmadığını bildiren araştırmalar da mevcuttur

(Benson ve Motes, 1982; Dufault, 1994).

$\mathrm{Bu}$ araştırma sonucunda elde edilen veriler değerlendirildiğinde 3 yaşında hasada başlanan bitkilerden bitki başına daha fazla sayıda ve kalınlıkta pazarlanabilir sürgün elde edilmiştir. Bununla birlikte ortalama sürgün çapı verileri incelendiğinde, 2 yaşındaki bitkilerden elde edilen sürgünlerin 3 yaşındaki bitkilerden elde edilene göre daha kalın (ortalama çap) olduğu bulunmuştur. Ayrıca, her ne kadar her bir hasat yılında 3 yaşında hasadına başlanan bitkilerden 2 yaşında hasada başlanan bitkilere kıyasla daha fazla sayıda sürgün elde edilmiş olsa da, 2 yaşında hasada başlanan bitkilerden takip eden yılda ilk kez 3 yaşında hasat edilen bitkilerin bir önceki yılda ürettiği sürgün sayısına benzer sayıda sürgün elde edilmiştir. Bu da ilk kez 2 yaşında hasat edilen bitkilerin erken hasattan dolayı olumsuz etkilenmediğini ve takip eden yıllarda artan sayıda sürgün üretebildiklerinin bir göstergesidir. O nedenle, dikimden bir yıl sonra yapılacak olan kuşkonmaz hasadı, özellikle küçük ölçekli yetiştiricilik ile uğraşan çiftçilere bir yıl daha erken para kazandırabilen yeni bir gelir kapısı olacaktır.

Bitkileri yazın hasada zorlamanın özellikle yetiştirme periyodunun uzun olduğu güney bölgelerde verime büyük katkısının olacağı ancak sürgün kalitesinin baharda yapılan hasatlara kıyasla daha düşük olacağı ifade edilmiş ve bu düşük sürgün kalitesinin asıl sebebinin köklerde biriken yetersiz karbonhidrat miktarı ile ilgili olduğu ifade edilmiştir (Dufault, 1994 ve 1995). ABD'nin Güney Carolina eyaleti koşullarında yapılan çalışmalarda kuşkonmazları yaz aylarinin ortasinda hasada zorlamanın uzun vadede sürgün kalitesi, sürgün sayısı ve bitkilerin hayatta kalma oranları açısından bahar hasadına kıyasla bir fark yaratmadığı ve dolayısıyla üretimin olmadığı yaz aylarında yaz hasadının bahar hasadına alternatif olabileceği bildirilmiştir (Dufault, 1994 ve 1995). Güney İtalya koşullarında baharda 90 gün süren kuşkonmaz hasadının, baharda 75 gün ve yazın 15 gün olarak iki kez yapılması halinde, verim ve kalite açısından fark yaratmadığı bulunmuştur (Caruso vd., 2012). Bununla birlikte yıl içerisinde ard arda yapılan hasatların, kış dinlenmesinden önce karbonhidrat rezervlerini doldurmak için gereken zamanı azalttığ da ifade edilmiştir (Brasher. 1956). ABD Güney Carolina eyaletinin kıyı bölgelerinde kuşkonmaz çeşidi 'UC $157 \quad F_{1}$ ' ile yapılan başka bir çalışmada, kuşkonmazı yaz hasadına zorlamanın normal bahar hasatlarına kıyasla daha yüksek ekonomik getirisinin olacağı ve bitkilerin daha uzun ömürlü ve sağlıklı olması açısından bir sorun teşkil etmeyeceği bildirilmiştir (Dufault, 1995).

$\mathrm{Bu}$ çalışmada yazın hasat edilen kuşkonmazlarda araştırmanın ilk yılında sürgün sayısı açısından bir fark gözlemlenmemiş, fakat takip eden yıllarda yazın hasat edilen bitkilerden daha az sayıda ve daha ince sürgün hasat edilmiştir. Ayrıca, baharda yapılan hasat sonrasında 8-12 $\mathrm{mm}$ çapında elde edilen sürgün sayısında yaz hasadına göre bir azalma meydana gelirken, pazarın tercih ettiği sürgün kalınlığı olan 12$16 \mathrm{~mm}$ ve $16 \mathrm{~mm}$ 'den kalın sürgün daha fazla sürgün elde edilmiştir. Kuşkonmaz köklerinde biriken karbonhidrat miktarları incelendiğinde, kış dinlenmesi öncesinde baharda hasat edilen bitkilerin yazın hasat edilenlere kıyasla istatistiksel anlamda önemli olmamakla beraber bir miktar daha yüksek seviyede karbonhidrat içeriğine sahip oldukları görülmüştür.

\section{SONUÇ ve ÖNERILLER}

Sonuç olarak normalde hasadının olmadığı yaz aylarında kusskonmaz hasadı yapmanın kalite ve verim açısından bir miktar kayıplara yol açtığı 
görülmüştür. Her ne kadar yaz aylarında verim ve kalitede bir miktar düşüş gözlense de üretici açısından bu kayıların yazın yapılacak olan hasattan elde edilecek olan daha yüksek gelirle kapatılması mümkün olacaktır. $\mathrm{O}$ nedenle üreticilerin bitkilerin bir kısmını baharda bir kısmını da yazın hasat etmeleri, elde edilecek olan gelirin sürekliliği ve aylara dağılımı açısından faydalı olacaktır. Ayrıca, bu araştırma kuşkonmaz bitkilerinin dikimi takip eden ilk sene hasat edilmesinin uzun vadede verim ve kalite üzerinde olumsuz bir etkisinin olmayacağını göstermiştir. Böylece üreticiler bir yll fazla beklemeden hasada başlayarak az da olsa kazanç elde etme olanağına sahip olacaklardır. Ancak yine bu konuda daha sağlıklı sonuçların elde edilmesi için farklı kuşkonmaz çeşitleri üzerinde yeni araştırmaların yürütülmesine ihtiyaç olduğu da belirtilmelidir.

\section{TEŞEKKÜR}

Yazarlar bu çalışmaya finansal destek veren Kahramanmaraş Sütçü İmam Üniversitesi Bilimsel Araştırma Projeleri Koordinasyon Birimi'ne (Proje No: 2016/ 5-36 M) teşekkürü bir borç bilirler.

\section{Çıkar Çatışması Beyanı}

Makale yazarları aralarında herhangi bir çıkar çatışması olmadığını beyan ederler.

\section{Araştırmacıların Katkı Oranı Beyan Özeti}

Yazarlar makaleye eşit oranda katkı sağlamış olduklarını beyan ederler.

\section{KAYNAKÇA}

Alan Ö 2017. Kuşkonmaz (Asparagus officinalis L. var. altilis). Tarım Türk Dergisi 89-94.

Benson B. Motes J 1982. Influence of Harvesting Asparagus the Year Following Planting on Subsequent Yield and Quality. HortScience 17: 744745.

Bhowmik PK. Matsui T 2003. Carbohydrate Status and Sucrose Metabolism in Asparagus Roots over an Extended Harvest Season. Asian Journal of Plant Sciences 2(12): 891-893.

Brasher EP 1956. Effects of Spring, Summer and Fall Cutting of Asparagus on Yield and Spear Weight. Proceedings of the Society for Horticultural Science 67: 377-383.

Caruso G. Villari G. Borrelli C. Russo G 2012. Effects of Crop Method and Harvest Seasons on Yield and Quality of Green Asparagus under Tunnel in Southern Italy. Advances in Horticultural Science 26(2): 51-58.

Drost DT 1997. Asparagus (The Physiology of Vegetable Crops, CAB International. Ed. Wien HC). pp. 621-635.
Drost. DT. 2013. Asparagus Nutrient Management. Factsheet.14/13. https://ahdb.org.uk/knowledgelibrary/asparagus-nutrient-management

Dufault RJ 1994. Impact of Forcing Summer Asparagus in Coastal South Carolina on Yield. Quality and Recovery from Harvest Pressure. Journal of the American Society for Horticultural Science 119(3): 396-402.

Dufault RJ 1995. Harvest Pressures Affect Forced Summer Asparagus Yield in Coastal South Carolina. Journal of the American Society for Horticultural Science 120: 14-20.

Eşiyok D 2012. Kışlık ve Yazlık Sebze Yetiştiriciliği. Meta Basım Matbaacılık Hizmetleri. Bornova. İzmir.

Gąsecka M. Krzesiński W. Stachowiak J. Knaflewski M 2009. The Effect of Temperature and Crown Size on Asparagus Yielding. Folia Horticulturae 21(1): 49-59.

Krzesiński W. Gąsecka M. Stachowiak J. Knaflewski M 2008. Plant Age Effect on Asparagus Yielding in Terms of Carbohydrate Balance. Folia Horticulturae 20(2): 29-38.

Lloyd J. McCollum J 1938. Yields of Asparagus as Affected by Severe Cutting of Young Plantations. Plant Breeding Reviews. Illinois Agricultural Experiment Station 448: 157-172.

Morris DL 1948. Quantitative Determination of Carbohydrates with Dreywoods Anthrone reagent. Science 107: 254-255.

Akan Ö 2014. Kuşkonmaz (Asparagus officinalis L.) Yetiştiriciliğinde Ülkemizin ve Dünyanın Durumu. Tralleis Elektronik Dergisi 3: 24-30.

Robb AR 1984. Physiology of Asparagus (Asparagus officinalis) as Treated to the Production of the Crop. New Zealand Journal of Experimental Agriculture 12: 251-260.

Shelton DM. Lacy ML 1980. Effect of Harvest Duration on Yield and on Depletion of Storage Carbohydrates in Asparagus Roots. Journal of the American Society for Horticultural Science 105: 332-335.

Shiomi N. 1992. Content of Carbohydrate and Activities of Fructosyltransferase and Invertase in Asparagus Roots during the Fructo-oligosaccharide and Fructo-polysaccharide Accumulating Season. New Phytologist 122: 421-432.

Takatori FH. Stillman JI. Souther FD 1970. Asparagus Yields and Plant Vigour as Influenced by Time and Duration of Cutting. California Agriculture 24(4): 810.

Wien HC 1997. The Physiology of Vegetable Physiology. CAB International. Madison. WI. USA.

Williams JB and Garthwaite JM 1973. The Effects of Seed and Crown Size and Length of Cutting Period on the Yield and Quality of Asparagus Grown on Ridges. Expoler Horticulture 25: 77-86. 